\title{
Association between active commuting and incident cardiovascular disease, cancer, and mortality: prospective cohort study
}

\author{
Carlos A Celis-Morales, ${ }^{1}$ Donald M Lyall,, ${ }^{2}$ Paul Welsh, ${ }^{1}$ Jana Anderson, ${ }^{2}$ Lewis Steell, ${ }^{1}$ Yibing Guo, \\ Reno Maldonado, ${ }^{1}$ Daniel F Mackay, ${ }^{2}$ Jill P Pell, ${ }^{2}$ Naveed Sattar, Jason M R Gill ${ }^{1}$
}

Institute of Cardiovascular and Medical Sciences, University of Glasgow, Glasgow G12 8TA, UK 2Institute of Health and Wellbeing, University of Glasgow, Glasgow, UK

Correspondence to: J M R Gill jason.gill@glasgow.ac.uk Additional material is published online only. To view please visit the journal online.

Cite this as: $B M J$ 2017;357:j1456 http://dx.doi.org/10.1136/bmj.j1456

Accepted: 16 March 2017

\section{ABSTRACT}

OBJECTIVE

To investigate the association between active commuting and incident cardiovascular disease (CVD), cancer, and all cause mortality.

DESIGN

Prospective population based study.

SETTING

UK Biobank.

PARTICIPANTS

263540 participants (106674 (52\%) women; mean age 52.6), recruited from 22 sites across the UK. The exposure variable was the mode of transport used (walking, cycling, mixed mode $v$ non-active (car or public transport)) to commute to and from work on a typical day.

\section{MAIN OUTCOME MEASURES}

Incident (fatal and non-fatal) CVD and cancer, and deaths from CVD, cancer, or any causes.

RESULTS

2430 participants died ( 496 were related to CVD and 1126 to cancer) over a median of 5.0 years (interquartile range 4.3-5.5) follow-up. There were 3748 cancer and 1110 CVD events. In maximally adjusted models, commuting by cycle and by mixed mode including cycling were associated with lower risk of all

\section{WHAT IS ALREADY KNOWN ON THIS TOPIC}

Active commuting, such as walking or cycling, has been recommended as a feasible way of incorporating greater levels of physical activity into daily life

A meta-analysis of 173146 participants reported that active commuting was associated with a lower risk of adverse cardiovascular outcomes

The work was limited by use of a heterogeneous range of cardiometabolic endpoints (including incident hypertension, diabetes, stroke, coronary heart disease, and cardiovascular disease (CVD)), and inconsistent adjustment for confounders between studies as well as no differentiation between commuting by walking and cycling

\section{WHAT THIS STUDY ADDS}

Commuting by cycling was associated with a lower risk of all cause mortality and adverse CVD and cancer outcomes, and walking commuting was associated with lower risk of CVD incidence and mortality, in a dose dependent manner and independent of a range of confounding factors

Mixed mode commuting including a cycle component was associated with a lower risk of all cause mortality and cancer outcomes

Policies designed to affect a population level modal shift to more active modes of commuting, particularly by cycle (eg, cycle lanes, city bike hire, subsidised cycle purchase schemes, and increasing provision for cycles on public transport) may present major opportunities for the improvement of public health cause mortality (cycling hazard ratio $0.59,95 \%$ confidence interval 0.42 to $0.83, \mathrm{P}=0.002$; mixed mode cycling $0.76,0.58$ to $1.00, P<0.05)$, cancer incidence (cycling $0.55,0.44$ to $0.69, \mathrm{P}<0.001$; mixed mode cycling $0.64,0.45$ to $0.91, P=0.01$ ), and cancer mortality (cycling $0.60,0.40$ to $0.90, \mathrm{P}=0.01$; mixed mode cycling $0.68,0.57$ to $0.81, \mathrm{P}<0.001)$. Commuting by cycling and walking were associated with a lower risk of CVD incidence (cycling 0.54, 0.33 to 0.88 , $\mathrm{P}=0.01$; walking $0.73,0.54$ to $0.99, \mathrm{P}=0.04$ ) and $C V D$ mortality (cycling $0.48,0.25$ to $0.92, \mathrm{P}=0.03$; walking $0.64,0.45$ to $0.91, P=0.01$ ). No statistically significant associations were observed for walking commuting and all cause mortality or cancer outcomes. Mixed mode commuting including walking was not noticeably associated with any of the measured outcomes.

\section{CONCLUSIONS}

Cycle commuting was associated with a lower risk of CVD, cancer, and all cause mortality. Walking commuting was associated with a lower risk of CVD independent of major measured confounding factors. Initiatives to encourage and support active commuting could reduce risk of death and the burden of important chronic conditions.

\section{Introduction}

Physical activity is declining worldwide, partly owing to reductions in active commuting (walking or cycling). ${ }^{12}$ Active commuting has been recommended as a practical way of incorporating more physical activity into daily life. ${ }^{3-6}$ A meta-analysis of 173146 participants reported that active commuting was associated with a lower risk of adverse cardiovascular outcomes, especially for women. ${ }^{7}$ However, the work was limited by a heterogeneous range of cardiometabolic endpoints (including hypertension, diabetes, stroke, coronary heart disease, and cardiovascular disease (CVD)), inconsistent adjustment for confounders, and no differentiation between walking and cycling. The authors of the study recommended further research on the association between active commuting and CVD. Evidence on the association of active commuting on mortality ${ }^{8-11}$ and cancer ${ }^{11-13}$ are equivocal, with available studies limited by relatively small numbers of participants. ${ }^{711}$ Evidence is limited on the associations of mixed mode commuting (a combination of active and non-active) on health outcomes. We used UK Biobank, a large, prospective, population based cohort study, to investigate the association between different types of active commuting and incident CVD, cancer, and all cause mortality. 


\section{Methods}

\section{Study design}

Between April 2007 and December 2010, UK Biobank recruited 502549 adults (5.5\% response rate) aged 40-69 from the general population. ${ }^{14}$ Participants attended one of 22 assessment centres across England, Scotland, and Wales. ${ }^{1516}$ We included the 263450 (52.4\%) participants who were in paid employment or self employed and did not always work at home. The main outcomes were deaths from any cause, CVD, and cancer, and incident fatal or non-fatal CVD and cancer. The exposure variable was the mode of transport used (non-active, cycling, walking, or mixed) to commute to work. Sociodemographic factors (sex, age, deprivation index, and ethnicity) smoking status, body mass index, leisure time, occupational and DIY physical activity, sedentary behaviour, and dietary intake were treated as potential confounders, as were a range of prevalent chronic diseases at baseline, in models that included participants with these conditions.

\section{Procedures}

Date and cause of death were obtained from death certificates held by the National Health Service (NHS) Information Centre for participants from England and Wales and NHS Central Register Scotland for participants from Scotland. Date and cause of hospital admissions were identified using record linkage to health episode statistics records for participants from England and Wales and Scottish morbidity records (SMR01) for participants from Scotland. At the time of analysis, mortality data were available up to 17 February 2014 for England and Wales and up to 31 December 2012 for Scotland. Therefore, for the analyses of mortality we censored follow-up at these dates, or at the date of death if this occurred earlier. Hospital admission data were available for the Scottish and English participants until 30 June 2012 and for the Welsh participants until 1 March 2011. Therefore, for incident CVD events, we classified end of follow-up as these dates unless preceded by death or admission. ${ }^{15} 16$ Incident CVD was defined as a hospital admission or death using ICD-10 (international classification of diseases, 10th revision) code I21, I60, I61, I63, or I64, and cancer as C0.0-C9.9, D3.7-9, or D4.0-8 recorded on the cancer registry, hospital, or death records. ${ }^{1516}$

At baseline, the mode of transportation was recorded using an electronic questionnaire completed by participants. They were asked "In a typical day, what types of transport do you use to get to and from work?" and could select one or more of the following options: car/ motor vehicle, walk, public transport, and cycle. We derived five commuting categories: non-active (car/ motor vehicle and/or public transport only); walking only; cycling (cycling, or cycling and walking); mixed mode walking (non-active plus walking); mixed mode cycling (non-active plus cycling, or non-active plus cycling and walking). For walking only and cycling, we derived the weekly commuting distance from the single commuting distance (multiplied by 2 to obtain round trip distance) and the weekly number of round trips reported by the participant. We used the median values to categorise participants into long and short weekly commuting distances for their commuting mode.

To further characterise participants' baseline characteristics according to commuting mode, we assessed self reported total physical activity according to the international physical activity questionnaire short form. ${ }^{17}$ We did not adjust for this, as total physical activity includes physical activity from commuting and so has substantial colinearity with our primary exposure. In a subset of 54378 participants, we obtained an objective accelerometer based measure of physical activity using a tri-axial accelerometer (AX3, Logging Accelerometer; Open Lab, Newcastle University) worn on the participants' wrist, and we assessed cardiorespiratory fitness in a subset of 39022 participants. ${ }^{18}$ These methods are described in more detail in the supplementary materials and elsewhere. ${ }^{18}$ The relatively small number of participants with these data and corresponding low number of events in this subset meant there was insufficient power to include these data as covariates in our outcome models.

\section{Statistical analyses}

The association between active commuting and health outcomes (all cause, CVD, and cancer mortality; incident CVD and cancer) was explored using Cox proportional hazard models, excluding participants with prevalent CVD and cancer at baseline from the CVD and cancer models, respectively. Models for all cause mortality excluded participants with a history of CVD or cancer. The reference category for all analyses was non-active commuting.

Analyses were adjusted for sex, age, ethnicity, Townsend deprivation index, comorbidities (longstanding illness, diabetes, hypertension, CVD, cancer, and depression), body mass index (coded as categorical variable based on the World Health Organization classification ${ }^{19}$ ), smoking, dietary intake (alcohol, fruit and vegetable, red meat, oily fish, poultry, and processed meat), time spent walking for pleasure, time spent undertaking strenuous sport, time spent in light and heavy DIY, level of occupational physical activity, and sedentary behaviour. Details of measurement of these covariates are described in the supplementary materials and elsewhere. ${ }^{1820}$ The proportional hazard assumption was checked by tests based on Schoenfeld residuals. All analyses were performed using STATA 14 statistical software (StataCorp).

\section{Patient involvement}

No patients were involved in setting the research question or the outcome measures, nor were they involved in developing plans for design or implementation of the study. No patients were asked to advise on interpretation or writing up of results. There are no plans to disseminate the results of the research to study participants or the relevant patient community.

\section{Results}

The median follow-up period was 5.0 years (interquartile range 4.3-5.5 years) for all cause, CVD, and cancer mortality and 2.1 (1.4-2.8) years for incident CVD and 
cancer. Over the follow-up period, a total of 2430 participants died (496 related to CVD and 1126 related to cancer); 1110 had incident CVD and 3748 cancer.

Table 1 summarises the main characteristics of the participants by commuting category. Tables 1 to 3 in the web appendix show that physical activity that was reported by participants and objectively measured as well as cardiorespiratory fitness were all highest in cycle commuters followed by mixed mode cycling commuters. Compared with non-active commuters, walking commuters had higher physical activity but not cardiorespiratory fitness.

Figure 1 shows the associations between commuting mode and prospective health outcomes. Cycle commuting (hazard ratio $0.59,95 \%$ confidence interval 0.42 to $0.83, \mathrm{P}=0.002$ ) and mixed mode commuting with a

\begin{tabular}{|c|c|c|c|c|c|}
\hline Characteristics & $\begin{array}{l}\text { Non-active (car and/ } \\
\text { or public transport) } \\
\text { ( } \mathrm{n}=206299 \text { ) }\end{array}$ & Walking $(n=14222)$ & Cycling* $(n=6751)$ & $\begin{array}{l}\text { Mixed mode: } \\
\text { walking }(n=23729)\end{array}$ & $\begin{array}{l}\text { Mixed mode: } \\
\text { cycling* }(n=12449)\end{array}$ \\
\hline Women & $106674(51.7)$ & $9849(69.3)$ & $4312(63.9)$ & $14927(62.9)$ & $4305(34.6)$ \\
\hline Mean (SD) age (years) & $57.75(7.0)$ & $53.01(7.0)$ & $51.36(7.0)$ & $52.31(6.9)$ & $50.30(6.7)$ \\
\hline \multicolumn{6}{|l|}{ Deprivation fifths: } \\
\hline First (least deprived) & $43578(21.2)$ & $1458(10.3)$ & $801(11.9)$ & 3717 (15.7) & $2344(18.9)$ \\
\hline Second & $42837(20.8)$ & $1800(12.7)$ & $971(14.4)$ & $3833(16.2)$ & 2307 (18.6) \\
\hline Third & $42652(20.7)$ & $2472(17.4)$ & $1257(18.6)$ & $4444(18.8)$ & $2501(20.1)$ \\
\hline Fourth & $41456(20.1)$ & $3655(25.7)$ & 1749 (25.9) & $5668(23.9)$ & 2848 (22.9) \\
\hline Fifth (most deprived) & $35469(17.2)$ & $4823(34.0)$ & $1967(29.2)$ & $6035(25.5)$ & 2434 (19.6) \\
\hline \multicolumn{6}{|l|}{ Household income (f): } \\
\hline$<18000$ & $18369(9.8)$ & $2750(22.2)$ & $668(10.6)$ & $2410(11.2)$ & $686(5.8)$ \\
\hline $18000-29999$ & $41430(22.2)$ & 3455 (27.9) & $1257(20.0)$ & $4742(22.0)$ & 1985 (16.9) \\
\hline $30000-51999$ & $60193(32.2)$ & $3438(27.7)$ & $1981(31.5)$ & $6440(29.8)$ & $3658(31.2)$ \\
\hline $52000-100000$ & $53692(28.7)$ & $2183(17.6)$ & $1837(29.2)$ & $6123(28.3)$ & $4093(34.9)$ \\
\hline$>100000$ & $13108(7.0)$ & $581(4.7)$ & $543(8.6)$ & $1891(8.8)$ & $1315(11.2)$ \\
\hline \multicolumn{6}{|l|}{ Ethnicity: } \\
\hline White & $192883(93.8)$ & 13309 (93.9) & $6471(96.3)$ & $22155(93.7)$ & $12024(96.9)$ \\
\hline South Asian & $4604(2.2)$ & $306(2.2)$ & $45(0.7)$ & $467(2.0)$ & $71(0.6)$ \\
\hline Black & $4174(2.0)$ & $231(1.6)$ & $55(0.8)$ & $505(2.1)$ & $108(0.9)$ \\
\hline Chinese & $751(0.4)$ & $64(0.5)$ & $33(0.5)$ & $80(0.3)$ & $27(0.2)$ \\
\hline Mixed background or others & $3316(1.6)$ & $263(1.9)$ & $117(1.7)$ & $442(1.9)$ & $184(1.5)$ \\
\hline \multicolumn{6}{|l|}{ Smoking status: } \\
\hline Never & $117725(57.2)$ & $8265(58.3)$ & $3862(57.3)$ & $14300(60.4)$ & $7326(59.0)$ \\
\hline Former & $65066(31.6)$ & $4237(29.9)$ & $2226(33.0)$ & $7245(30.6)$ & $4047(32.6)$ \\
\hline Current & $22924(11.1)$ & $1671(11.8)$ & $653(9.7)$ & $2120(9.0)$ & $1052(8.5)$ \\
\hline \multicolumn{6}{|l|}{ Obesity related markers: } \\
\hline Mean (SD) body mass index & $27.51(4.8)$ & $26.51(4.6)$ & $25.22(3.6)$ & $26.86(4.7)$ & $26.10(3.8)$ \\
\hline \multicolumn{6}{|l|}{ Body mass index categories: } \\
\hline Underweight (<18.5) & $842(0.4)$ & $110(0.8)$ & $68(1.0)$ & $147(0.6)$ & $56(0.5)$ \\
\hline Normal weight (18.5-24.9) & $65618(31.9)$ & $5860(41.3)$ & $3465(51.5)$ & $9031(38.2)$ & $5259(42.3)$ \\
\hline Overweight (25.0-29.9) & $87712(42.7)$ & $5489(38.7)$ & $2585(38.4)$ & $9487(40.1)$ & $5352(43.1)$ \\
\hline Obese $(\geq 30.0)$ & $51291(25.0)$ & $2721(19.2)$ & $616(9.2)$ & $4996(21.1)$ & $1755(14.1)$ \\
\hline Mean (SD) waist circumference (cm) & $90.26(13.5)$ & $86.33(12.8)$ & $85.84(11.3)$ & $87.79(13.1)$ & $88.07(11.6)$ \\
\hline Central obesity & $66012(32.1)$ & $4000(28.2)$ & $901(13.4)$ & $6995(30.0)$ & $2227(17.9)$ \\
\hline Mean (SD) \% body fat & $30.84(8.4)$ & $31.70(8.5)$ & $24.73(7.7)$ & $31.42(8.5)$ & $25.93(7.7)$ \\
\hline \multicolumn{6}{|l|}{ Fitness and physical activity (mean (SD)):: } \\
\hline Fitness (METs) $\dagger$ & $9.32(3.3)$ & $8.94(3.2)$ & $11.79(3.5)$ & $9.46(3.2)$ & $11.55(3.2)$ \\
\hline Grip strength (kg) & $32.56(11.1)$ & $28.84(9.9)$ & $36.26(10.4)$ & $30.24(10.1)$ & $37.18(10.8)$ \\
\hline Objective weekday total physical activity $(\mathrm{mg} /$ day) $\dagger$ & $28.59(8.5)$ & $30.52(9.1)$ & $32.79(10.2)$ & $29.18(8.1)$ & $31.55(9.4)$ \\
\hline Objective weekend total physical activity (mg/day) $\dagger$ & $28.64(10.1)$ & $29.48(10.5)$ & $33.28(12.2)$ & $29.17(9.9)$ & $32.86(12.5)$ \\
\hline Self reported total physical activity (MET, h/week) & $44.78(69.7)$ & $55.63(72.9)$ & $77.08(82.7)$ & $42.37(56.9)$ & $59.04(69.1)$ \\
\hline Walking for pleasure (min/week) & $87.0(142.7)$ & $108.0(164.5)$ & $91.4(144.2)$ & $89.1(138.9)$ & $92.1(143.4)$ \\
\hline Light DIY (min/week) & $98.0(183.8)$ & $78.9(155.9)$ & $86.5(158.2)$ & $91.6(163.4)$ & $81.2(152.4)$ \\
\hline Heavy DIY (min/week) & $85.2(187.5)$ & $61.1(142.9)$ & $70.8(147.8)$ & $72.6(147.6)$ & $57.7(127.9)$ \\
\hline Strenuous sport (min/week) & $132.3(138.2)$ & $139.9(148.2)$ & $160.2(172.4)$ & $148.3(152.9)$ & $123.3(137.1)$ \\
\hline \multicolumn{6}{|l|}{ Job involves manual work: } \\
\hline Never or rarely & $132534(64.3)$ & $8098(57.0)$ & $4274(63.3)$ & $8291(66.6)$ & $17036(71.8)$ \\
\hline Sometimes & $44458(21.5)$ & $3692(26.0)$ & $1443(21.3)$ & $2677(21.5)$ & $4482(18.9)$ \\
\hline Usually & $14472(7.0)$ & $1152(8.1)$ & $492(7.3)$ & $848(6.8)$ & $1159(4.9)$ \\
\hline
\end{tabular}




\begin{tabular}{|c|c|c|c|c|c|}
\hline Characteristics & $\begin{array}{l}\text { Non-active (car and/ } \\
\text { or public transport) } \\
\text { ( } \mathrm{n}=206299 \text { ) }\end{array}$ & Walking (n=14 222) & Cycling ${ }^{\star}(n=6751)$ & $\begin{array}{l}\text { Mixed mode: } \\
\text { walking }(n=23729)\end{array}$ & 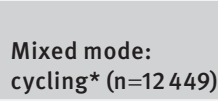 \\
\hline Always & $14670(7.1)$ & $1258(8.9)$ & $541(8.0)$ & $629(5.1)$ & $1034(4.4)$ \\
\hline Achieving physical activity guidelines & $105210(51.0)$ & $7737(54.4)$ & $6088(90.2)$ & $11867(50.0)$ & $9894(79.5)$ \\
\hline Mean (SD) total sedentary behaviour (h/day) & $5.17(2.40)$ & $4.03(2.14)$ & $3.62(2.13)$ & $4.27(2.09)$ & $4.24(2.10)$ \\
\hline \multicolumn{6}{|l|}{ Dietary intakes (mean (SD)):: } \\
\hline Total energy intake (kcal/day) & $2153.95(675.6)$ & $2111.67(643.2)$ & $2341.17(703.4)$ & $2162.48(647.3)$ & $2349.57(742.9)$ \\
\hline Alcohol intake (\% of energy intake) & $5.30(6.7)$ & $4.64(6.3)$ & $5.06(6.0)$ & $5.09(6.3)$ & $5.58(6.3)$ \\
\hline Fruit and vegetable intake (g/day) & $316.67(190.2)$ & $335.89(199.5)$ & $364.69(209.8)$ & $338.03(189.7)$ & $347.74(199.3)$ \\
\hline Oily fish (portion/week) & $1.02(1.0)$ & $1.03(1.0)$ & $1.08(1.1)$ & $1.07(1.0)$ & $1.07(1.0)$ \\
\hline Red meat (portion/week) & $1.92(1.4)$ & $1.78(1.4)$ & $1.67(1.3)$ & $1.81(1.3)$ & $1.78(1.3)$ \\
\hline Processed meat (portion/week) & $1.90(1.1)$ & $1.74(1.1)$ & $1.74(1.1)$ & $1.78(1.0)$ & $1.87(1.1)$ \\
\hline \multicolumn{6}{|l|}{ Health status: } \\
\hline Diabetes history & $7879(3.8)$ & $427(3.0)$ & $110(1.6)$ & 739 (3.1) & $216(1.7)$ \\
\hline Hypertension & $41822(20.3)$ & $2721(19.2)$ & 869 (12.9) & $4569(19.3)$ & $1682(13.5)$ \\
\hline Cancer history & $11620(5.7)$ & $856(6.0)$ & $286(4.2)$ & $1297(5.5)$ & $571(4.6)$ \\
\hline Longstanding illness & $51615(25.6)$ & $3276(23.7)$ & $1286(19.4)$ & $5838(25.2)$ & $2496(20.4)$ \\
\hline CVD & $48550(23.5)$ & $3142(22.1)$ & $998(14.8)$ & $5127(21.6)$ & 1911 (15.4) \\
\hline Depression history & $65780(32.1)$ & $4949(35.1)$ & $1782(26.5)$ & 8279 (35.1) & 3579 (28.9) \\
\hline
\end{tabular}

MET=basal metabolic equivalent; $C V D=$ cardiovascular disease.

${ }^{*}$ Cycling included cycling, or cycling and walking; mixed mode cycling included non-active plus cycling, or cycling and walking.

tFor those with data available for active commuting, 39022 participants had available data on cardiorespiratory fitness and 54378 had data on objectively measured physical activity.

\begin{tabular}{|c|c|c|c|c|c|}
\hline \multicolumn{3}{|l|}{ All cause mortality } & $\begin{array}{c}\text { Hazard ratio } \\
(95 \% \mathrm{CI})\end{array}$ & $\begin{array}{l}\text { Hazard ratio } \\
(95 \% \mathrm{Cl})\end{array}$ & \multirow[t]{2}{*}{$P$ value } \\
\hline Non-active (reference) & 1379 & 186763 & & 1.00 & \\
\hline Walking & 103 & 12848 & & 1.03 (0.84 to 1.26$)$ & 0.78 \\
\hline Cycling & 37 & 6301 & $\longrightarrow$ & $0.59(0.42$ to 0.83$)$ & 0.002 \\
\hline Mixed mode: walking & 122 & 21765 & & $0.96(0.80$ to 1.15$)$ & 0.66 \\
\hline Mixed mode: cycling & 58 & 11588 & & $0.76(0.58$ to 1.00$)$ & 0.05 \\
\hline \multicolumn{6}{|l|}{ CVD mortality } \\
\hline Non-active (reference) & 420 & 199141 & & 1.00 & \\
\hline Walking & 18 & 13780 & & 0.64 (0.45 to 0.91$)$ & 0.01 \\
\hline Cycling & 8 & 6613 & $\rightarrow$ & $0.48(0.25$ to 0.92$)$ & 0.03 \\
\hline Mixed mode: walking & 29 & 23142 & & $0.78(0.53$ to 1.15$)$ & 0.21 \\
\hline Mixed mode: cycling & 20 & 12200 & & 0.92 (0.58 to 1.46$)$ & 0.72 \\
\hline \multicolumn{6}{|l|}{ CVD incidence } \\
\hline Non-active (reference) & 1029 & 198536 & & 1.00 & \\
\hline Walking & 51 & 13749 & & 0.73 (0.54 to 0.99$)$ & 0.04 \\
\hline Cycling & 18 & 6603 & - & 0.54 (0.33 to 0.88$)$ & 0.01 \\
\hline Mixed mode: walking & 86 & 23085 & & 0.84 (0.66 to 1.07$)$ & 0.16 \\
\hline Mixed mode: cycling & 42 & 12178 & & $0.82(0.59$ to 1.14$)$ & 0.24 \\
\hline \multicolumn{6}{|l|}{ Cancer mortality } \\
\hline Non-active (reference) & 912 & 193205 & & 1.00 & \\
\hline Walking & 74 & 13230 & & $1.10(0.86$ to 1.41$)$ & 0.45 \\
\hline Cycling & 25 & 6428 & $\longrightarrow$ & $0.60(0.40$ to 0.90$)$ & 0.01 \\
\hline Mixed mode: walking & 81 & 22296 & & 0.97 (0.77 to 1.22$)$ & 0.80 \\
\hline Mixed mode: cycling & 31 & 11822 & $\longrightarrow$ & 0.64 (0.45 to 0.91$)$ & 0.01 \\
\hline \multicolumn{6}{|l|}{ Cancer incidence } \\
\hline Non-active (reference) & 3504 & 190617 & & 1.00 & \\
\hline Walking & 241 & 13065 & $\rightarrow$ & $0.93(0.81$ to 1.07$)$ & 0.30 \\
\hline Cycling & 89 & 6364 & $\rightarrow$ & 0.55 (0.44 to 0.69$)$ & $<0.001$ \\
\hline Mixed mode: walking & 333 & 22044 & & $0.99(0.88$ to 1.11$)$ & 0.87 \\
\hline \multirow[t]{3}{*}{ Mixed mode: cycling } & 135 & 11718 & $\rightarrow-$ & 0.68 (0.57 to 0.81$)$ & $<0.001$ \\
\hline & & & 0.5 & & \\
\hline & \multicolumn{3}{|c|}{ Lower risk } & & \\
\hline
\end{tabular}

Fig 1 | Hazard ratio for all cause mortality, cardiovascular disease (CVD) incidence and mortality, and cancer incidence and mortality by commuting mode cycling component $(0.76,0.58$ to $1.00, \mathrm{P}=0.05)$ were both associated with a statistically significant lower risk of all cause mortality compared with non-active commuting. There were no significant associations for walking or mixed mode commuting including walking for all cause mortality. For CVD mortality, both walking (0.64, 0.45 to $0.91, \mathrm{P}=0.01)$ and cycling $(0.48,0.25$ to 0.92 , $\mathrm{P}=0.03)$ were associated with a lower risk than non-active commuting. The incidence of CVD was similar for walking $(0.73,0.54$ to $0.99, \mathrm{P}=0.04)$ and cycling $(0.54$, 0.33 to $0.88, \mathrm{P}=0.01)$. No significant associations with CVD outcomes were observed for mixed mode commuting. Cycle commuting (0.60, 0.40 to $0.90, \mathrm{P}=0.01)$ and mixed mode commuting including cycling $(0.64,0.45$ to $0.91, \mathrm{P}=0.01$ ) were both associated with a lower risk of cancer mortality. Cancer incidence was similar for cycling (0.55, 0.44 to $0.69, \mathrm{P}<0.001)$ and mixed mode commuting including cycling (0.68, 0.57 to 0.81 , $\mathrm{P}<0.001)$. No distinctive associations were found for walking or mixed mode commuting including walking for cancer outcomes.

Figure 2 shows that among walking commuters, there were distinct dose-response trends for CVD incidence and mortality but not for other outcomes by weekly commuting distance. Figure 3 shows that among cycling commuters there were distinct dose-response trends in all outcomes by weekly commuting distance.

\section{Discussion}

Commuting by walking was associated with a lower risk of CVD incidence and mortality. However, commuting by cycling was associated with the lowest risk of these as well as lower risks of all cause mortality and cancer, with dose dependent relations for all outcomes. Mixed mode commuting was associated with some benefits 


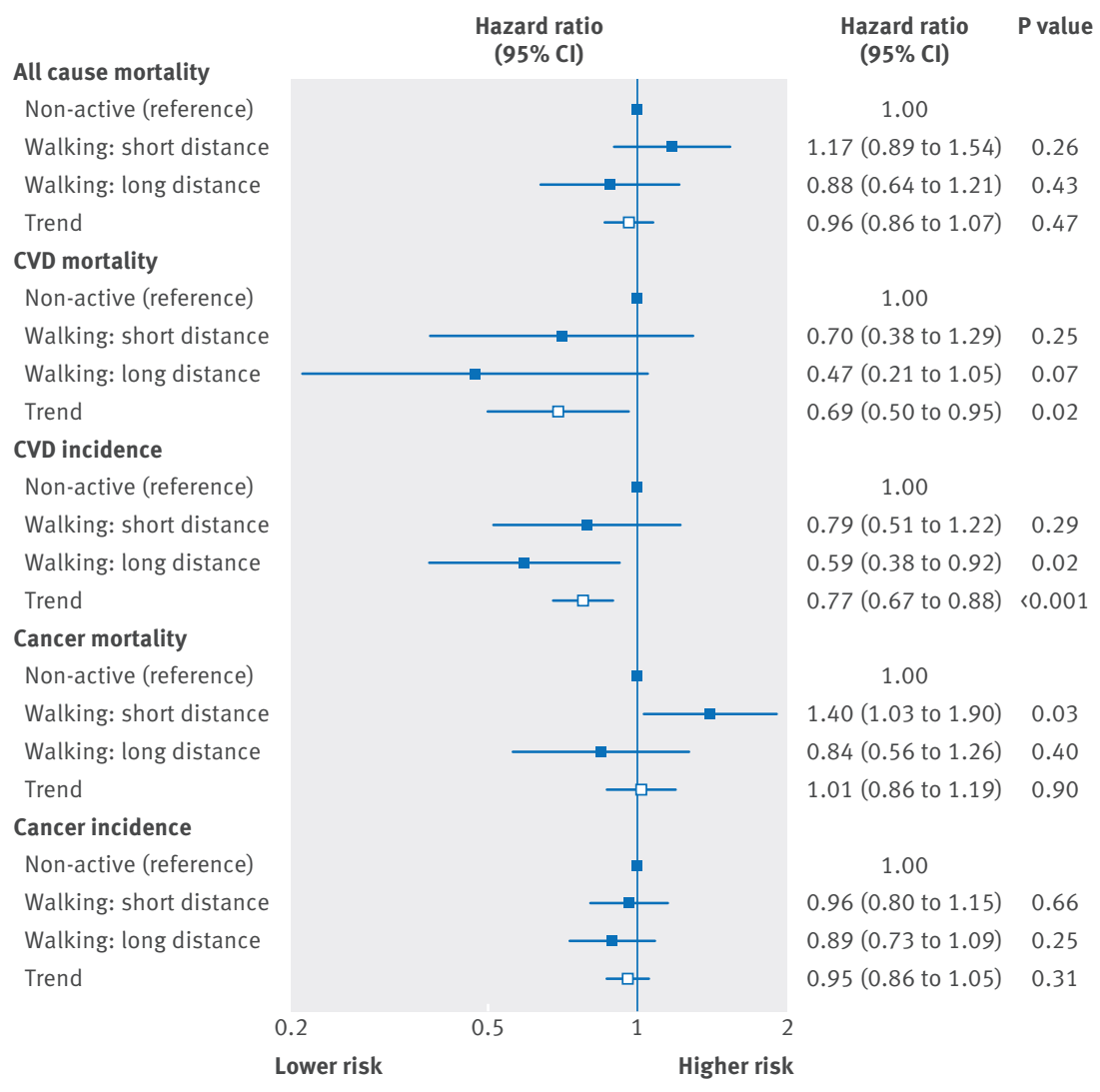

Fig 2 | Hazard ratio for all cause mortality, cardiovascular disease (CVD) incidence and mortality, and cancer incidence and mortality by weekly walking commuting distance

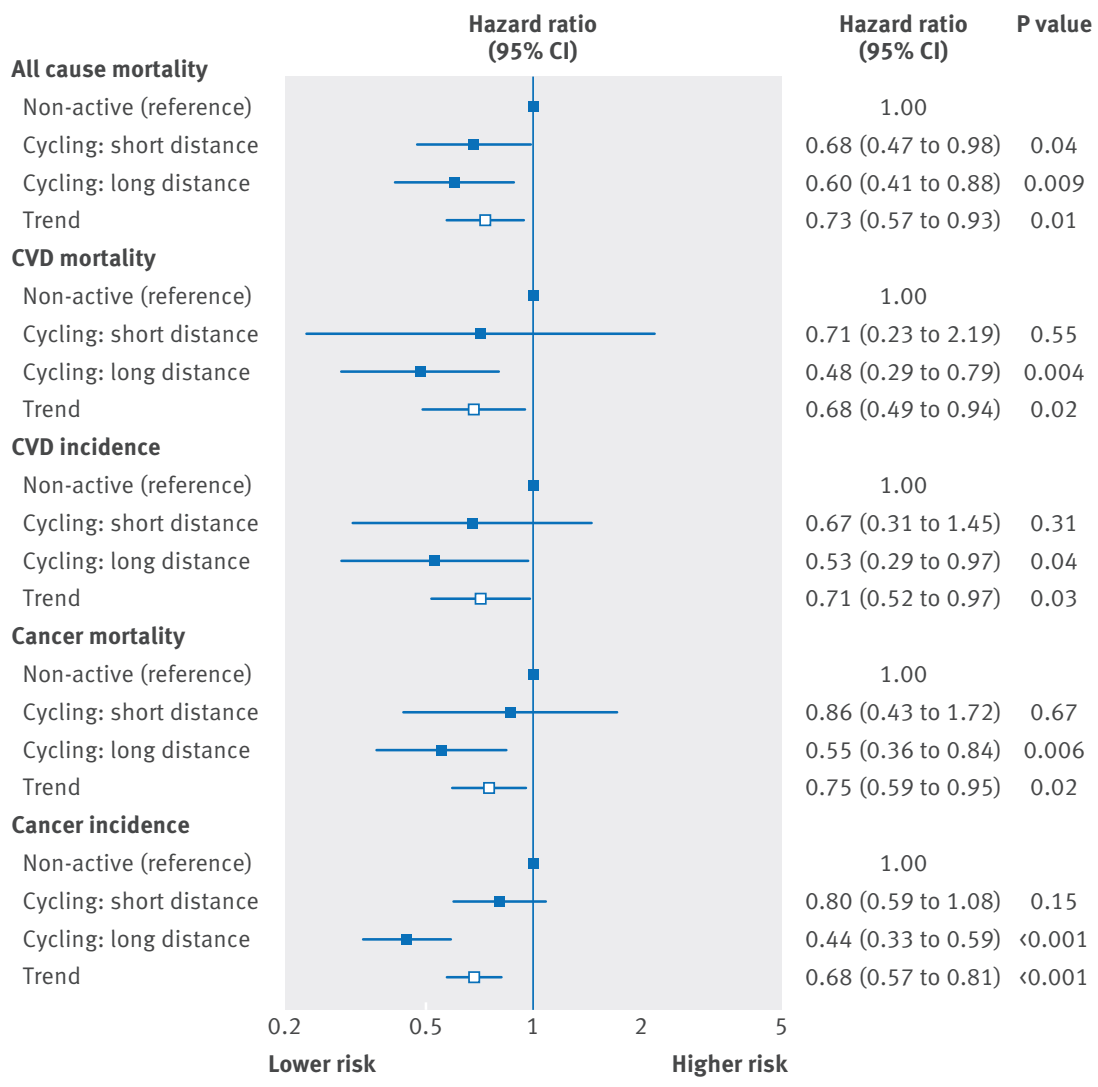

Fig 3 | Hazard ratio for all cause mortality, cardiovascular disease (CVD) incidence and mortality, and cancer incidence and mortality by weekly cycling commuting distance but only if the active component comprised cycling. These associations were independent of sex, age, deprivation, ethnicity, smoking status, recreational and occupational physical activity, sedentary behaviour, dietary patterns, and other confounding factors, including body mass index and comorbidities. These results are relevant, because active commuting on a daily basis is an important contributor to total physical activity. ${ }^{3-6}$ Encouraging active commuting, particularly by cycling, may be a viable approach to deliver health benefits related to physical activity at the population level.

The risk reductions associated with active commuting are likely to be related to their contribution to overall daily physical activity, and potentially to cardiorespiratory fitness, for which the associations with lower mortality, CVD incidence, and cancer incidence are well established. ${ }^{1821-24}$ Cycling commuters, and mixed mode cycling commuters, had greater overall physical activity and fitness than walking commuters. This finding may reflect the greater exercise intensity of cycling compared with walking. ${ }^{25}$ While approximately $90 \%$ of cycle commuters and approximately $80 \%$ of mixed mode cycling commuters achieved current physical activity guidelines, only $54 \%$ of walking commuters and approximately $50 \%$ of mixed mode walking commuters did; a similar proportion to non-active commuters (51\%). The findings support the benefits of active commuting, particularly commuting with a cycling component. To produce meaningful benefits for walking commuters, longer distances may be needed. In the present cohort, a lower risk for CVD incidence was only evident among the walking commuters who covered more than six miles a week (equivalent to two hours of weekly commuting by walking at a typical pace of three miles an hour).

The strong evidence base for both overall and leisure related physical activity, ${ }^{2627}$ contrasts with relatively few and conflicting studies of non-leisure physical activity, such as active commuting, and prospective health outcomes. $^{7-13}$ The large population size of the present study provided sufficient power to compare different forms of active commuting, including mixed modes of commuting with active and non-active components, in relation to a range of outcomes. In particular, previous studies showing benefits of active commuting have often been in countries where levels of active commuting are high and the supporting infrastructure is good (eg, Nordic countries and China). ${ }^{7-13}$ The data from this study extended the evidence base to the UK, where active commuting is less common. This has important policy implications, suggesting that policies designed to affect a population level modal shift to more active modes of commuting, particularly cycle commuting (eg, cycle lanes, city bike hire, subsidised cycle purchase schemes, and increasing provision for cycles on public transport), present major opportunities for the improvement of public health.

\section{Strengths and weaknesses of this study}

UK Biobank is relatively representative of the general population for age, sex, ethnicity, and deprivation 
within the age range recruited but is not representative in other regards, such as prevalence of obesity and comorbidities, which may indicate a healthy volunteer selection bias. ${ }^{28}$ While this limits the ability to generalise prevalence rates, it should be possible to generalise the estimates of the magnitude of associations. ${ }^{142829}$ We were able to adjust for a wide range of health, demographic, and behavioural confounders. Mode and distance of commuting was self reported, rather than objectively measured; however, any errors introduced by misclassification of commuting behaviour would have acted to attenuate the association between active commuting and health outcomes. ${ }^{30}$ As is the case for any observational study, residual confounding is always possible and associations may not imply causation. A further limitation was that we were not able to derive weekly commuting distance for mixed mode commuters owing to a lack of information on how much of the journey was undertaken using active transport. Additionally, fitness and objectively measured physical activity was only available for a subset of the cohort with active commuting data, which limited the possibility of adding these variables as covariates in our models. We adjusted for occupational physical activity and some aspects of leisure time physical activity (walking for pleasure, strenuous sport, and DIY), but do not have a measure of overall non-commuting activity, so may not have fully adjusted for potential contributions of non-commuting physical activity on the measured health outcomes.

\section{Conclusion}

Commuting undertaken totally or partially by bicycle was associated with a lower risk of a range of adverse health outcomes. Commuting by walking was associated with a lower risk of adverse CVD outcomes. The findings, if causal, suggest population health may be improved by policies that increase active commuting, particularly cycling, such as the creation of cycle lanes, cycle hire or purchase schemes, and better provision for cycles on public transport.

This research was conducted using the UK Biobank resource. We thank the participants of the UK Biobank.

Contributors: CACM, JPP, NS, and JMRG contributed to the conception and design of the study, advised on all statistical aspects, and interpreted the data. CACM performed the statistical analysis, assisted by $L S$, YG, and RM. CACM, JPP, NS, and JMRG drafted the manuscript. CACM, DML, PW, JA, LS, YG, RM, DFM, JPP, NS, and JMRG reviewed the manuscript and approved the final version to be published. CACM, JPP, NS, and JMRG had full access to all of the data in the study and take responsibility for the integrity of the data and the accuracy of the data analysis. JPP, NS, and JMRG contributed equally to this work and are joint senior authors. CACM, JPP, NS, and JMRG are the guarantors.

Funding: The UK Biobank was supported by the Wellcome Trust, Medical Research Council, Department of Health, Scottish government, and Northwest Regional Development Agency. It has also had funding from the Welsh Assembly government and British Heart Foundation. The research was designed, conducted, analysed, and interpreted by the authors entirely independently of the funding sources.

Competing interests: All authors have completed the ICMJE uniform disclosure form at www.icmje.org/coi_disclosure.pdf and declare: no support from any organisation for the submitted work; no financial relationships with any organisations that might have an interest in the submitted work in the previous three years; no other relationships or activities that could appear to have influenced the submitted work.
Ethical approval: UK Biobank received ethical approval from the North West Multi-centre Research Ethics Committee (REC reference: 11/NW/03820). All participants gave written informed consent before enrolment in the study, which was conducted in accord with the principles of the Declaration of Helsinki.

Data sharing: Researchers can apply to use the UK Biobank resource and access the data used. No additional data are available.

Transparency: The manuscript's guarantors (CACM, JPP, NS, and JMRG) affirm that the manuscript is an honest, accurate, and transparent account of the study being reported; that no important aspects of the study have been omitted; and that any discrepancies from the study as planned (and, if relevant, registered) have been explained.

This is an Open Access article distributed in accordance with the terms of the Creative Commons Attribution (CC BY 4.0) license, which permits others to distribute, remix, adapt and build upon this work, for commercial use, provided the original work is properly cited. See:

http://creativecommons.org/licenses/by/4.0/

1 Pucher J, Buehler R, Bassett DR, Dannenberg AL. Walking and cycling to health: a comparative analysis of city, state, and international data. Am J Public Health 2010;100:1986-92. doi:10.2105/AJPH.2009.189324

2 Bassett DR Ir. Pucher I, Buehler R, Thompson DL, Crouter SE. Walking, cycling, and obesity rates in Europe, North America, and Australia. J Phys Act Health 2008:5:795-814. doi:10.1123/jpah.5.6.795.

3 Walking and cycling: local measures to promote walking and cycling as forms of travel or recreation. NICE. 2012. www.nice.org.uk/ guidance/ph41 (accessed.

4 Audrey S, Procter S, Cooper AR. The contribution of walking to work to adult physical activity levels: a cross sectional study. Int / Behav Nutr Phys Act 2014;11:37. doi:10.1186/1479-5868-11-37.

5 Petrunoff N, Rissel C, Wen LM. The effect of active travel interventions conducted in work settings on driving to work: A systematic review. J Transp Health 2016;3:61-76. doi:10.1016/j.jth.2015.12.001.

6 Ogilvie D, Foster CE, Rothnie H, et al. Scottish Physical Activity Research Collaboration. Interventions to promote walking: systematic review. BMJ 2007;334:1204-7. doi:10.1136/bmj.39198.722720.BE.

7 Hamer M, Chida Y. Active commuting and cardiovascular risk: a meta-analytic review. Prev Med 2008:46:9-13. doi:10.1016/j. ypmed.2007.03.006

8 Andersen LB, Schnohr P, Schroll M, Hein HO. All-cause mortality associated with physical activity during leisure time, work, sports, and cycling to work. Arch Intern Med 2000;160:1621-8. doi:10.1001/ archinte.160.11.1621.

9 Hu G, Eriksson J, Barengo NC, et al. Occupational, commuting, and leisure-time physical activity in relation to total and cardiovascular mortality among Finnish subjects with type 2 diabetes. Circulation 2004;110:666-73. doi:10.1161/01.CIR.0000138102.23783.94.

10 Besson H, Ekelund U, Brage S, et al. Relationship between subdomains of total physical activity and mortality. Med Sci Sports Exerc 2008;40:1909-15. doi:10.1249/MSS.0b013e318180bcad.

11 Oja P, Titze S, Bauman A, et al. Health benefits of cycling: a systematic review. Scand / Med Sci Sports 2011:21:496-509. doi:10.1111/j.1600-0838.2011.01299.x

12 Matthews CE, Jurj AL, Shu XO, et al. Influence of exercise, walking, cycling, and overall nonexercise physical activity on mortality in Chinese women. Am J Epidemiol 2007;165:1343-50. doi:10.1093/aje/ kwm088.

13 Hou L, Ji B-T, Blair A, Dai Q Gao YT, Chow WH. Commuting physical activity and risk of colon cancer in Shanghai, China. Am J Epidemiol 2004;160:860-7. doi:10.1093/aje/kwh301.

14 Collins R. What makes UK Biobank special?Lancet 2012;379:1173-4 doi:10.1016/50140-6736(12)60404-8.

15 Palmer LJUK. UK Biobank: bank on it. Lancet 2007;369:1980-2. doi:10.1016/S0140-6736(07)60924-6

16 Sudlow C, Gallacher J, Allen N, et al. UK biobank: an open access resource for identifying the causes of a wide range of complex diseases of middle and old age. PLoS Med 2015;12:e1001779. doi:10.1371/journal.pmed.1001779.

17 Guo W, Bradbury KE, Reeves GK, Key TJ. Physical activity in relation to body size and composition in women in UK Biobank. Ann Epidemiol 2015;25:406-413.e6. doi:10.1016/i.annepidem.2015.01.015.

18 Celis-Morales CA, Lyall DM, Anderson J, et al. The association between physical activity and risk of mortality is modulated by grip strength and cardiorespiratory fitness: evidence from 498135 UK-Biobank participants. Eur Heart/2016-ehw249 doi:101093/eurhearti/ehw249.

19 Obesity: preventing and managing the global epidemic. Report of a WHO consultation. WHO. 2000. http://apps.who.int/iris/ bitstream/10665/42330/1/WHO_TRS_894.pdf (accessed 3 Jun 2016).

20 Anderson J,, Celis-Morales CA, Mackay DF, et al. Adiposity among 132479 UK Biobank participants; contribution of sugar intake vs other macronutrients. Int J Epidemiol 2016:dyw173. doi:10.1093/ije/dyw173. 
21 Robsahm TE, Falk RS, Heir T, et al. Measured cardiorespiratory fitness and self-reported physical activity: associations with cancer risk and death in a long-term prospective cohort study. Cancer Med 2016;5:2136-44. doi:10.1002/cam4.773.

22 Schmid D, Leitzmann MF. Cardiorespiratory fitness as predictor of cancer mortality: a systematic review and meta-analysis. Ann Oncol 2015;26:272-8. doi:10.1093/annonc/mdu250.

23 Barry VW, Baruth M, Beets MW, Durstine JL, Liu J, Blair SN. Fitness vs. fatness on all-cause mortality: a meta-analysis. Prog Cardiovasc Dis 2014:56:382-90. doi:10.1016/j.pcad.2013.09.002

24 Kodama S, Saito K, Tanaka S, et al. Cardiorespiratory fitness as a quantitative predictor of all-cause mortality and cardiovascular events in healthy men and women: a meta-analysis. JAMA 2009;301:2024-35. doi:10.1001/jama.2009.681.

25 Ainsworth BE, Haskell WL, Herrmann SD, et al. 2011 Compendium of Physical Activities: a second update of codes and MET values. Med Sci Sports Exerc 2011:43:1575-81. doi:10.1249/ MSS.0b013e31821ece12.
26 Sofi F, Capalbo A, Cesari F, Abbate R, Gensini GF. Physical activity during leisure time and primary prevention of coronary heart disease: an updated meta-analysis of cohort studies. Eur / Cardiovasc Prev Rehabil 2008;15:247-57. doi:10.1097/HJR.0b013e3282f232ac.

27 Global recommendations on physical activity for health. WHO. 2010.

28 Fry A, Littlejohns T], Sudlow C, et al. OP41 The representativeness of the UK Biobank cohort on a range of sociodemographic, physical, lifestyle and health-related characteristics. J Epidemiol Community Health 2016;70(Suppl 1):A26doi:10.1136/jech-2016-208064.41.

29 Manolio TA, Collins R. Enhancing the feasibility of large cohort studies. JAMA 2010;304:2290-1. doi:10.1001/jama.2010.1686.

30 Celis-Morales CA, Perez-Bravo F, Ibañez L, Salas C, Bailey ME, Gill JM. Objective vs. self-reported physical activity and sedentary time: effects of asurement method on relationships with risk biomarkers. PLoS One 2012;7:e36345. doi:10.1371/journal.pone.0036345.

Supplementary appendix: additional information 